\title{
Surface initiated ATRP: Synthesis and Characterization of Functional Polymers Grafted on Modified Cellulose Beads
}

\author{
Md. Ashaduzzaman ${ }^{1,2, *}$, Kei Ishikura ${ }^{2}$, Masayo Sakata ${ }^{2}$, Masashi Kunitake ${ }^{2,3}$ \\ ${ }^{1}$ Department of Applied Chemistry \& Chemical Engineering, University of Dhaka, \\ Dhaka 1000, Bangladesh, \\ ${ }^{2}$ Graduate School of Science and Technology, Kumamoto University, 2-39-1 Kurokami, \\ Kumamoto 860-8555, Japan \\ ${ }^{3}$ Core Research for Evolutional Science and Technology, Japan Science and Technology Agency, \\ Kawaguchi Center Building, 4-1-8 Honcho, Kawaguchi, Saitama 332-0012, Japan \\ *E-mail address: azaman01@du.ac.bd
}

\begin{abstract}
Atom transfer radical polymerization (ATRP) was employed to synthesize novel polymer particles. The surface of porous polymeric cellulose beads was modified by sodium hydroxide, 2chloromethyloxirane, ethylenediamine and 2-bromo-2-methylpropionyl bromide successively in order to activate the beads surface so that it can play an important role as an initiator for ATRP reaction. ATRP on the modified cellulose beads surface was carried out with styrene and sodium $p$ styrenesulphonate monomers in the presence of non aqueous and aqueous phases respectively. The polymer products on the substrate surface were characterized by elemental analysis (EA), attenuated total reflectance-infrared (ATR-IR) spectroscopy and carbon ${ }^{13}$ - nuclear magnetic resonance $\left({ }^{13} \mathrm{C}\right.$ NMR).
\end{abstract}

Keywords: atom transfer radical polymerization (ATRP); cellulose beads; surface modification; grafting from; ionic polymer

\section{INTRODUCTION}

ATRP is a type of living polymerization that allows for control of the polymer molecular weight and molecular weight distribution ${ }^{1}$. Living polymerization has been used to graft substrates including silicon wafers ${ }^{2}$, chromatographic beads ${ }^{3,4}$ and particles ${ }^{5}$. The "grafting from" approach involves polymerization from surface bound initiator and results in living polymer grafts with high surface density ${ }^{6,7}$. Here, we introduce the synthesis and characterization of functional polymer-grafted cellulose beads based on "grafting from" ATRP with styrene and ionic monomer sodium $p$-styrenesulfonate (SSS). The control of surfaces by the modification in terms of sort of polymers, graft density and graft length would be crucial to design novel chromatographic separation systems. 


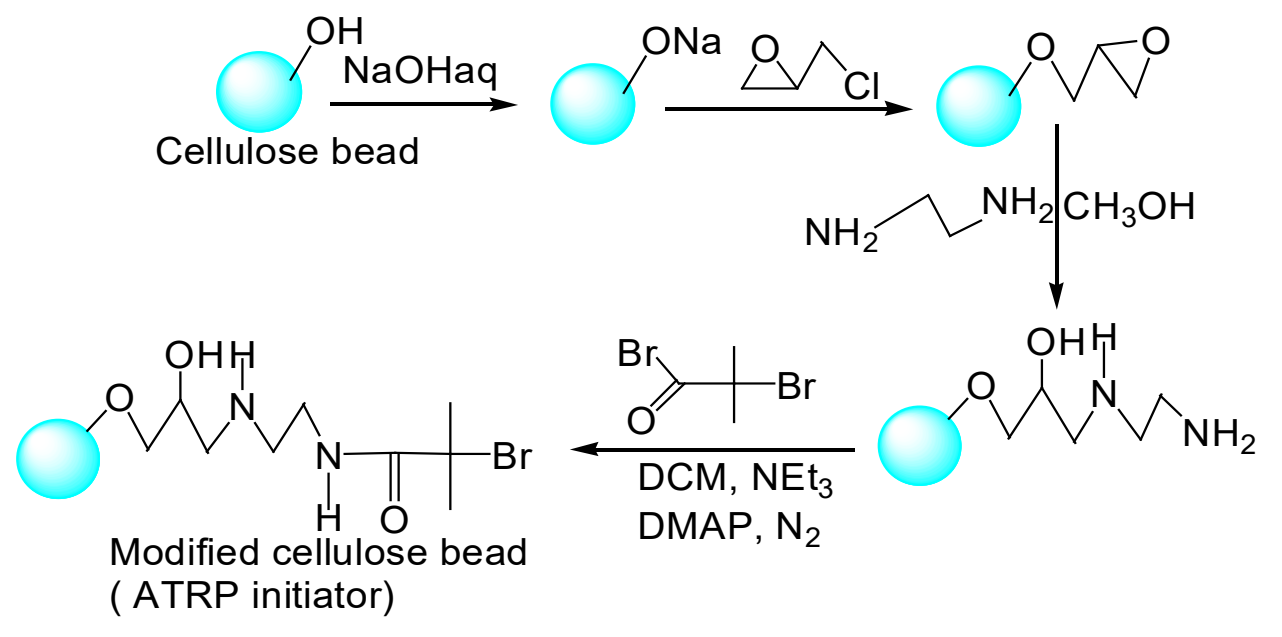

Scheme 1. Modification of cellulose beads by different means in order to synthesize the ATRP initiator.

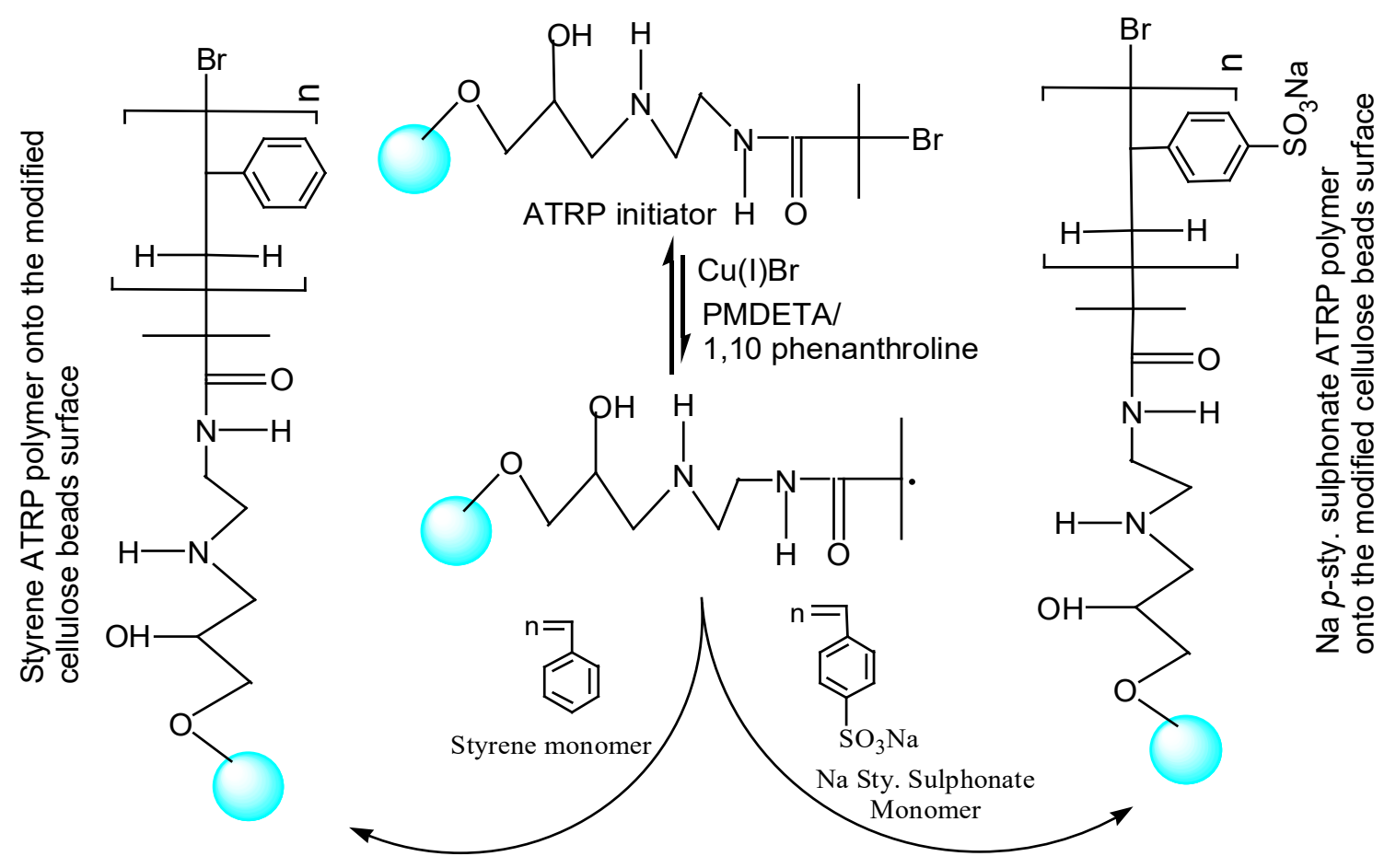

Scheme 2. Synthetic strategy of styrene and $\mathrm{Na} p$-styrenesulfonate polymers onto the modified cellulose beads surface via surface initiated ATRP.

\section{EXPERIMENTAL}

\section{1. Materials and methods}

Cellulose beads supplied from Chisso Corporation was taken in a reactor fitted with a stirrer. NaOHaq. solution was added to it and placed in an oil bath at $30{ }^{\circ} \mathrm{C}$. After $1 \mathrm{~h}$, required quantity of 2-chloromethyl oxirane was introduced in the reactor and stirred for 
extended $2 \mathrm{~h}$ period of time. The product was washed with water and methanol several times successively and filtered by a glass filter. Then the product was transferred in a reactor at 40 ${ }^{\circ} \mathrm{C} .20 \%$ EDA was added to it and reaction was conducted for $4 \mathrm{~h}$. After that, the reaction mass was washed with water and methanol till to remove ammonia smell and filtered by a glass filter and the product was preserved in ethanol. Cell-Epox-EDA was washed by dry methanol and dried in a vacuum dryer at $40{ }^{\circ} \mathrm{C}$. 4-Dimethylaminopyridine (DMAP) was taken in a bottle and dried Cell-Epox-EDA was washed with dehydro-dichloromethane (DCM) and entered in the bottle. Then DCM, triethylamine $\left(\mathrm{NEt}_{3}\right)$ and 2-bromo-2methylpropionylbromide were put into the bottle in nitrogen environment. The bottle was shaken at room temperature for $12 \mathrm{~h}$ by a mechanical shaker.

The product was then washed with water and methanol thoroughly and filtered by a glass filter and preserved in ethanol. Styrene was purified by distillation to remove inhibitors. Dried initiator grafted cellulose, $\mathrm{Cu}(\mathrm{I}) \mathrm{Br}$, a ligand, Styrene monomer and dimethylformamide were taken in an Eggplant flask and stirred immediately to make a homogeneous mixture.

The mixture was degassed by pump and backfilled with $\mathrm{N}_{2}$ gas five times and kept in a preheated oil bath fitted with a condenser, a stirrer and $\mathrm{N}_{2}$ gas balloon at $110{ }^{\circ} \mathrm{C}$ for 3-day. Then the reaction mass was washed with convenient solvents and preserved in ethanol. SSS monomer and water-pyridine mixture were taken in a reaction flask, dissolved monomer completely and degassed by pump. $\mathrm{Cu}(\mathrm{I}) \mathrm{Br}$, a ligand and dried initiator grafted cellulose were charged and mixed well to till a homogeneous mixture. The flask was closed, degassed by pump and backfilled with $\mathrm{N}_{2}$ gas five times and placed in an preheated oil bath fitted with a condenser, a stirrer and $\mathrm{N}_{2}$ gas balloon at $80{ }^{\circ} \mathrm{C}$ for 5 -day. Then the product was washed with suitable solvents and preserved in ethanol.

\section{RESULTS AND DISCUSSION}

Scheme I shows the reaction path for modification of cellulose particles. In scheme 2, various ATRP polymerizations onto the modified cellulose surface are illustrated. The chemical compositions of the cellulose beads surface at various stages of surface modifications were determined by elemental analysis as shown in Table 1.

The $\mathrm{N} \%$ of Cell-Epox-EDA proved the introduction of 2-chloromethyl oxirane and following EDA. The decreasing of $\mathrm{C} / \mathrm{N}$ ratio at the step of reaction with initiator moiety also proved the introduction. The drastically increased value of $\mathrm{C} / \mathrm{N}$ ratio of styrene ATRP and SSS ATRP indicated the polymer grafting.

Table 1. Results of elemental analysis.

\begin{tabular}{llllc}
\hline Particles & $\mathrm{H} \%$ & $\mathrm{C} \%$ & $\mathrm{~N} \%$ & $\mathrm{C} / \mathrm{N}$ \\
\hline Cellulose beads & 6.7 & 41.1 & 0 & --- \\
\hline Cellulose-2-chloromethyl oxirane & 6.8 & 42.3 & 0 & --- \\
\hline Cell-Epox-EDA & 6.9 & 42.1 & 0.83 & 50.72 \\
\hline Initiator grafted cellulose & 6.7 & 42.0 & 0.94 & 44.68 \\
\hline Styrene ATRP & 6.7 & 50.0 & 0.86 & 58.14 \\
\hline SSS ATRP & 5.7 & 41.7 & 0.42 & 99.29 \\
\hline
\end{tabular}




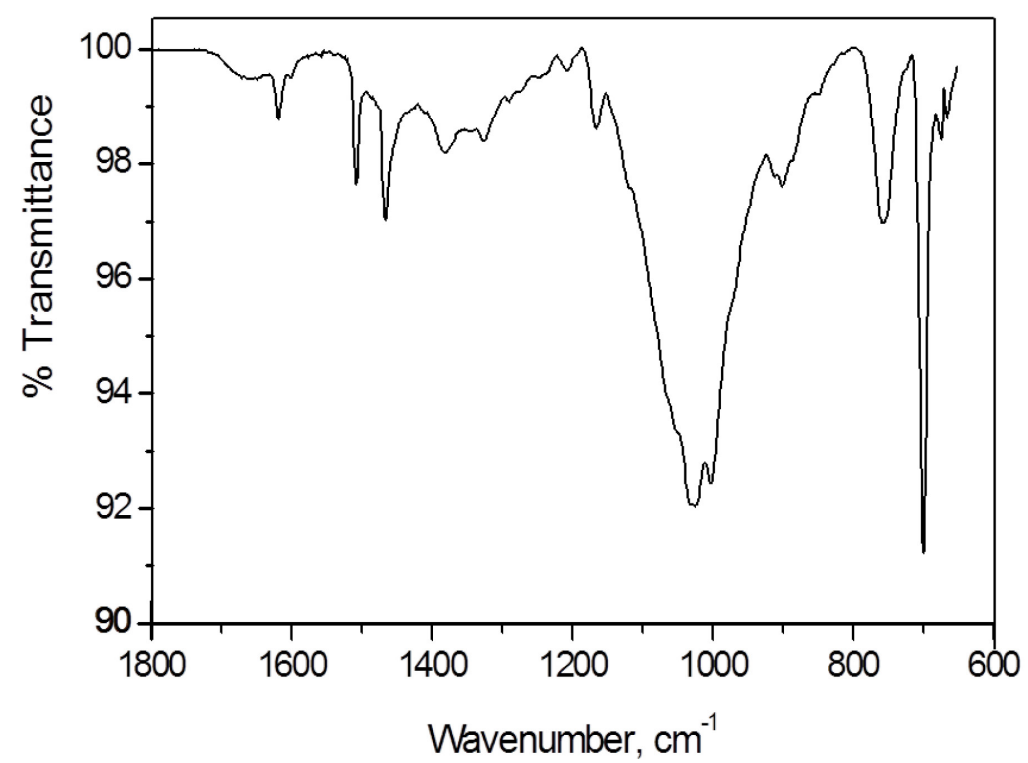

Fig. 1. The spectrum of ATR-IR spectroscopy of poly(styrene) ATRP onto the modified cellulose beads surface.

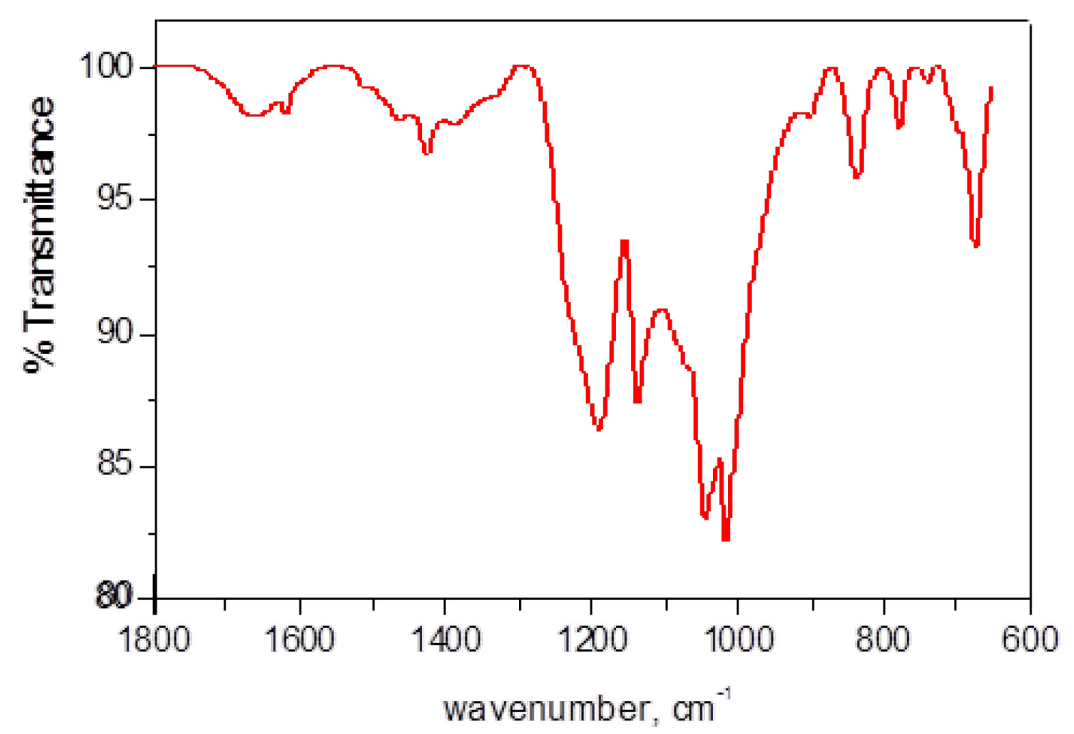

Fig. 2. The spectrum of ATR-IR spectroscopy of poly(Na $p$-styrenesulphonate) ATRP onto the modified cellulose beads surface.

In ATR-IR spectroscopy (Fig. 1), absorption bands at 1601.88, 1493.05 \& 1452.14 $\mathrm{cm}^{-1}$ were attributed to $-\mathrm{C}=\mathrm{C}-$ of benzene and $679.08 \& 753.84 \mathrm{~cm}^{-1}$ for monosubstituted benzene ring of styrene. In SSS ATRP (Fig. 2), absorption bands at 1600.88, 1495.98, 1449.38 and $831.31 \mathrm{~cm}^{-1}$ showed the presence of disubstituted benzene ring. The absorption bands at $1178 \& 1125 \mathrm{~cm}^{-1}$ revealed the presence of $-\mathrm{SO}_{3}$ group of $\mathrm{Na} p$-styrenesulfonate in the polymer ${ }^{8}$. 


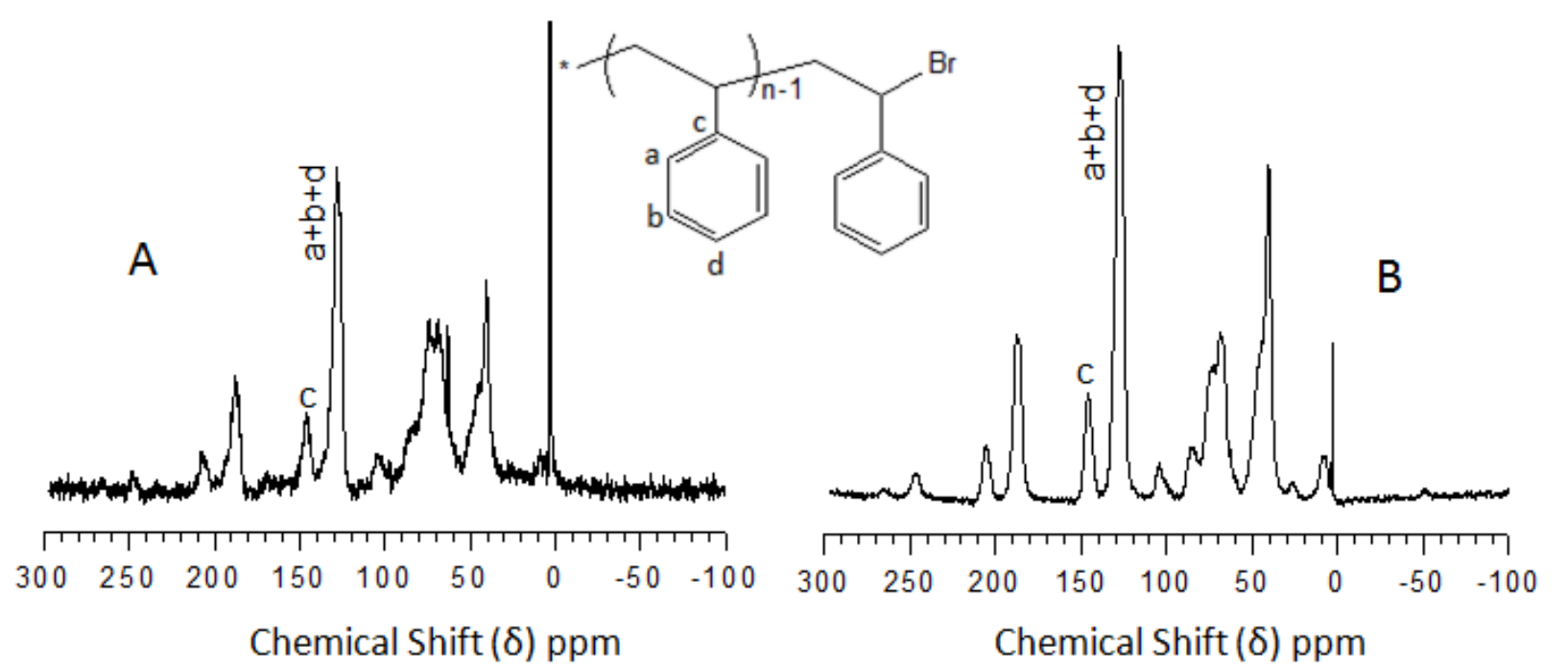

Fig. 3. Solid ${ }^{13} \mathrm{C}-\mathrm{NMR}$ spectra of Cell-g-polystyrene: DD mass (A) and CP mass (B).

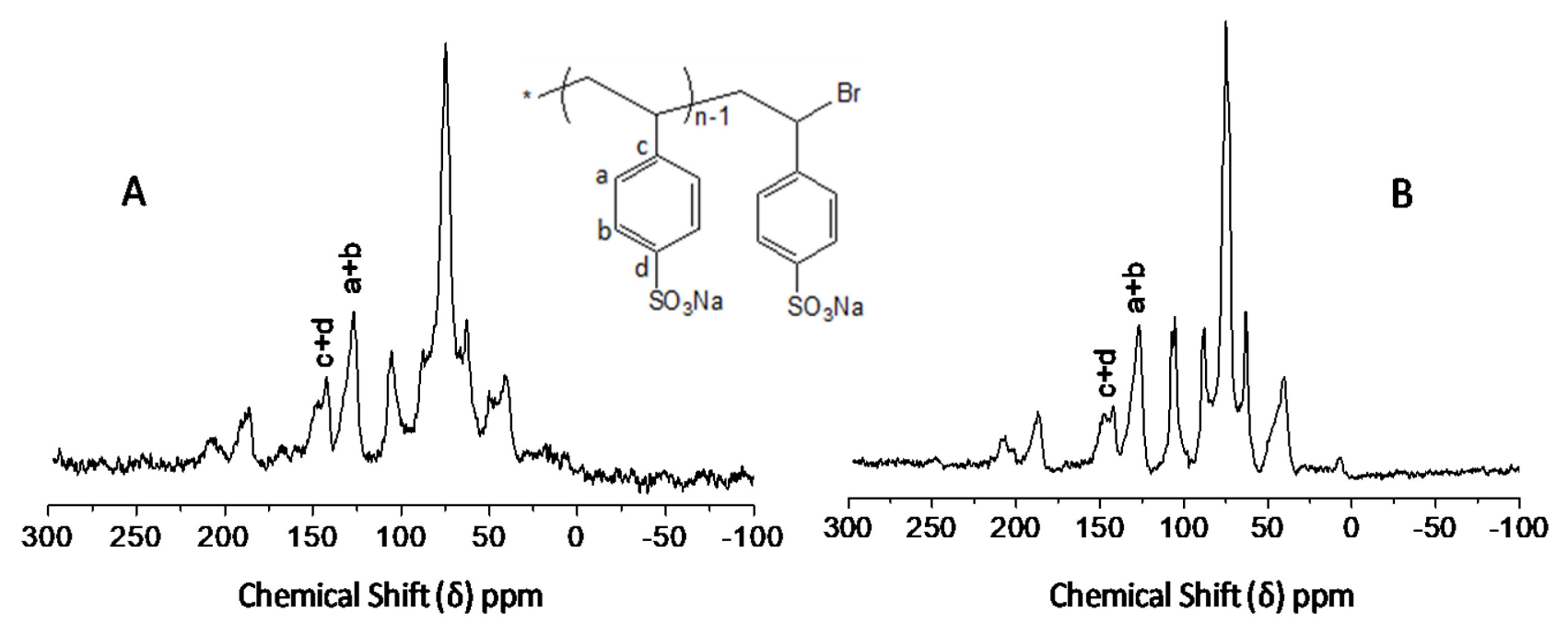

Fig. 4. Solid ${ }^{13} \mathrm{C}-\mathrm{NMR}$ spectra of Cell-g-poly(Na styrenesulfonate) DD mass (A) and CP mass (B)

The grafted copolymer beads were further characterized by ${ }^{13} \mathrm{C}-\mathrm{NMR}$ in the solid state (DD mass and CP mass). The chemical shift for four carbon atoms of polystyrene except ortho position occupied carbons from $\delta=120.12-140.20 \mathrm{ppm}$ was observed as shown in Fig. 3 . The signal for carbon atoms of $C 1$ position was obtained at $\delta=140.25-157.18 \mathrm{ppm}$. On the other hand, the signal of the cellulose backbone carbon was very strong, as a result the carbon of $-\mathrm{CH}_{3}$ group from initiator couldn't be detected. Whereas, the chemical shift for four carbon atoms of Na-styrenesulfonate except ortho \& para positions occupied carbons from $\delta$ $=117.23-137.21$ ppm was observed as shown in Fig. 4. The doublet signals for carbon atoms of $\mathrm{C} 1$ and $\mathrm{C} 4$ positions were obtained at $\delta=137.22-156.14 \mathrm{ppm}$. The signal of the cellulose backbone carbon was very strong, as a result the carbon of $-\mathrm{CH}_{3}$ group from initiator couldn't be detected. 


\section{CONCLUSION}

In summary, we have demonstrated ATRP graft polymerization of styrene and sodium $p$-styrenesulfonate polymers from the surface of cellulose beads. The particles modified by various polymers with controlled $\mathrm{Mw}$ would be widely used for not only liquid chromatographic separation but also other bio-applications.

\section{References}

[1] K. Matyjaszewski, J. Xia, J. Chem. Rev. 101 (2001) 2921-2990.

[2] D. Nystrom, P. Antoni, E. Malmstrom, M. Whittaker, A. Hult, 2005; DOI: $10.1002 /$ marc. 200400617.

[3] D. Xiao, M. J. Wirth, Macromolucules 35 (2002) 2919-2925.

[4] A. K. Mallik, M. M. Rahman, M. Czaun, M. Takafuji, H. Ihara, Chemistry Letters 36 (2007) 1460-1461.

[5] G. Zheng, H. D. H. Stover, Macromolecules 35 (2002) 6826-6834.

[6] B. Zhao, W. J. Brittain, Prog. Polym. Sci., 25 (2000) 667-710.

[7] F. Chang, K. Yamabuki, K. Onimura, T. Oishi, Polymer Journal 40 (2008) 1170-1179.

[8] A. M. Balachandra, G. L. Baker, M. L. Bruening, Journal of Membrane Science 227 (2003) 1-14. 